\title{
Flower Basket Retrieval: Utilization of a Device with a Unique Design for Endoscopic Rescue in Cases Involving Proximal Migration of Pancreatic Duct Stents
}

\author{
Vincent Zimmer ${ }^{1,2}$ \\ ${ }^{1}$ Department of Medicine, Marienhausklinik St. Josef Kohlhof, Neunkirchen, ${ }^{2}$ Department of Medicine II, Saarland University Medical Center, \\ Saarland University, Homburg, Germany
}

The use of pancreatic stents has become a powerful ancillary strategy in post-endoscopic retrograde cholangiopancreatography (ERCP) pancreatitis (PEP) prophylaxis. ${ }^{1}$ The myriad of rescue approaches for difficult biliary access, such as transpancreatic sphincterotomy or needle-knife precut, rely on tangible competency associated with pancreatic stenting. ${ }^{2}$ However, despite the obvious overall benefits, the risk of proximal migration is estimated to be about $5 \%$, posing different levels of complexity for retrieval as determined by duct width, depth of proximal migration, and most critical, downstream strictures. ${ }^{3,4}$ While the distinct mechanisms of proximal stent migration remain elusive in many circumstances, anatomical factors and/or biliary instrumentation, such as that after complex biliary duct access following pancreatic duct stenting, appear to represent key factors. For example, stent insertion beyond the pancreatic genu and/or accross an ansa pancreatica is not recommended when using short straight stents because the related traction forces may favor proximal migration. Reported extraction techniques are broadly categorized into over-the-wire (Soehendra retriever, the so-called Lasso technique using mini snares, etc.) or "freehand" approaches, using, for example, Dormia baskets or alongside-the-stent balloon

Received: February 23, 2019 Revised: March 31, 2019

Accepted: April 1, 2019

Correspondence: Vincent Zimmer

Department of Medicine, Marienhausklinik St. Josef Kohlhof, Klinikweg 1-5, 66539 Neunkirchen, Germany

Tel: +49-6821-3632070, Fax: +49-6821-3632624, E-mail: vincent.zimmer@gmx.de ORCID: https://orcid.org/0000-0002-6298-4717

(cc) This is an Open Access article distributed under the terms of the Creative Commons Attribution Non-Commercial License (http://creativecommons.org/ licenses/by-nc/3.0) which permits unrestricted non-commercial use, distribution, and reproduction in any medium, provided the original work is properly cited. inflation. ${ }^{5,6}$ Various ancillary devices have been used in individual case reports, including a grasping tripod or modified snare with a cut plastic sheath. ${ }^{7.8}$ In addition, in some instances, delayed extraction of migrated stents has been described, implementing a bridging concept by first inserting another pancreatic duct stent alongside the migrated stent to reduce the risk of post-ERCP PEP. Such a concept may be reasonable to gain time in, for example, critically ill patients and/or when referral to a higher-level center is considered.

From this perspective, a novel variant extraction technique is presented utilizing a specifically designed $20-\mathrm{mm}$, 8-wire basket initially devised for grasping small, floating biliary stones (FlowerBasket; Olympus, Hamburg, Germany). In the past 3 months, this "flower basket retrieval" technique was successfully applied in 2 consecutive patients with short straight, double-flapped 5-Fr stents (MTW, Wesel, Germany) as our standard stent type for PEP.

In normal pancreatic duct anatomy, a conventional basket cannot be fully deployed; thus, the chance of successful extraction decreases tremendously. In contrast, the unique design of the FlowerBasket (Fig. 1A; left) relative to that of the conventional 4-wire basket (right) may be superior for limited-space instrumentation in small-caliber pancreatic ducts as assessed by initial judicious contrast application as an anatomical roadmap. After successful grasping of the distal end during forward movements of the partially opened basket with the small proximal wire mesh (Fig. 1B), the stent was extracted (Fig. 1C) Finally, a single pigtail pancreatic drainage is reinserted to reduce the manipulation-associated risk of PEP and remigration (Fig. 1D). Likewise, in patient 2, Flower basket capture (Fig. 2A) and transpapillary extraction (Fig. 2B) of 

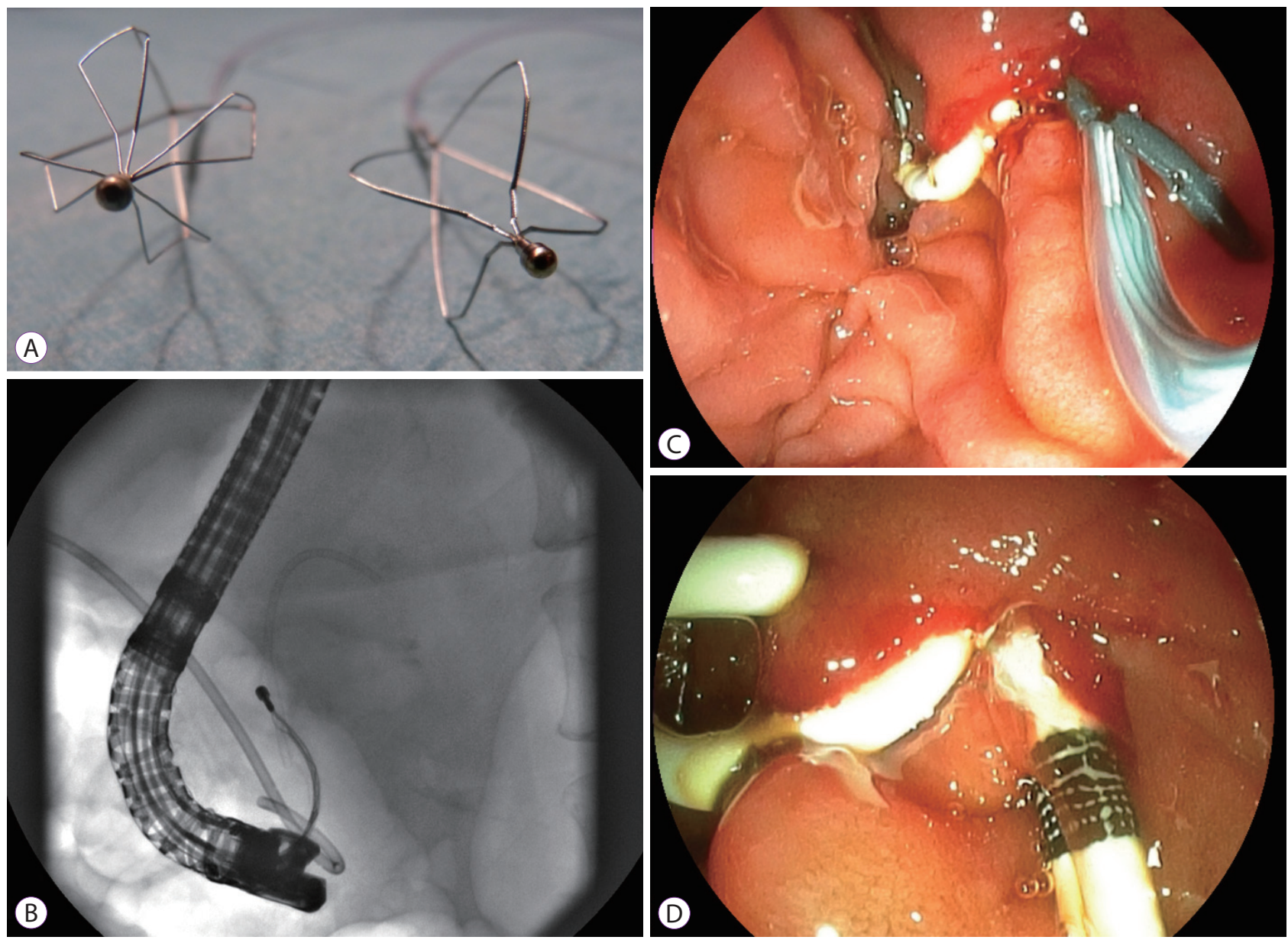

Fig. 1. (A) Comparison between the 8-wire FlowerBaseket with small proximal mesh pockets (left) and a more conventionally designed basket (right). Patient 1: (B) Fluoroscopic illustration of the intraductal capture of a discretely migrated 5-Fr pancreatic stent below the level of the genu. (C) Successful transpapillary stent extraction and $(D)$ reinsertion of a single-pigtail stent to reduce the risk of post-interventional pancreatitis and remigration.
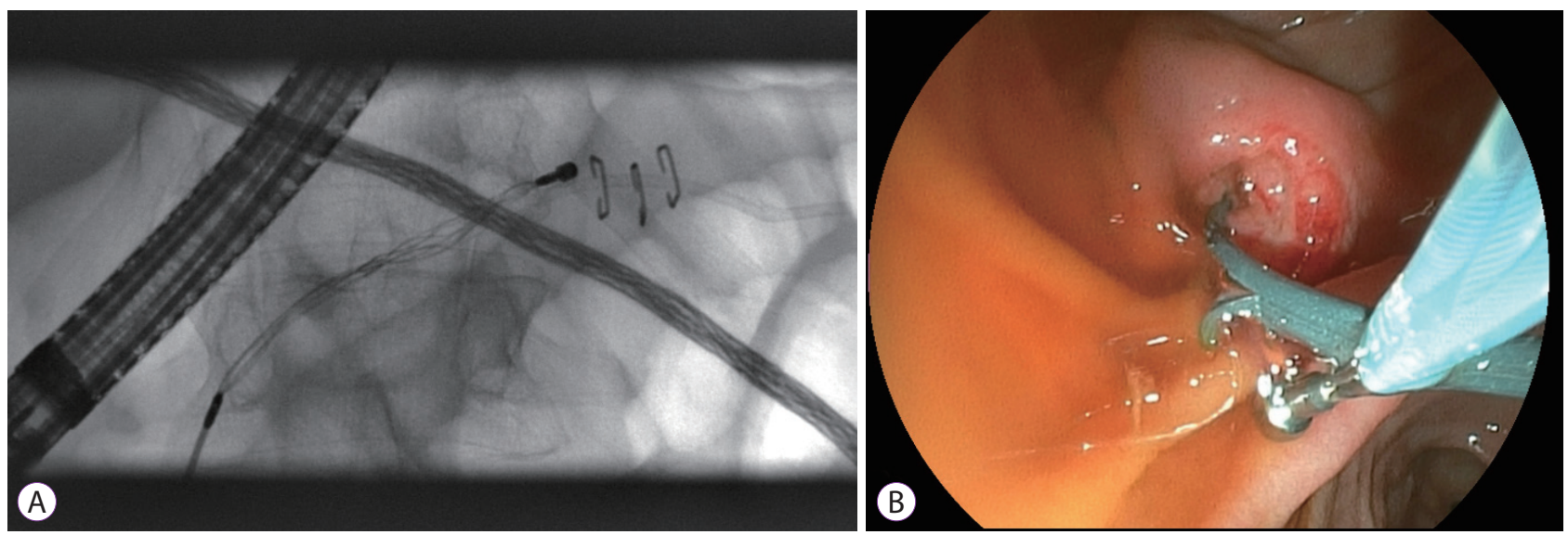

Fig. 2. Patient 2: (A) Grasping of the distal stent end in a more proximally migrated stent above the genu with (B) successful endoscopic extraction through the papilla.

a more proximally migrated stent beyond the pancreatic genu were successfully performed. Under mandatory pancreatic restenting with single pigtails, both patients had an uncompli- cated clinical course without clinical signs of PEP and/or relevant increases in pancreatic enzyme levels (serum amylase, 221 and $98 \mathrm{U} / \mathrm{L}$, respectively). 
Conflicts of Interest

The author has no financial conflicts of interest.

\section{REFERENCES}

1. Dumonceau JM, Andriulli A, Elmunzer BJ, et al. Prophylaxis of post-ERCP pancreatitis: European Society of Gastrointestinal Endoscopy (ESGE) guideline - updated June 2014. Endoscopy 2014;46:799-815.

2. Liao WC, Angsuwatcharakon $\mathrm{P}$, Isayama $\mathrm{H}$, et al. International consensus recommendations for difficult biliary access. Gastrointest Endosc 2017;85:295-304.

3. Price LH, Brandabur JJ, Kozarek RA, Gluck M, Traverso WL, Irani S. Good stents gone bad: endoscopic treatment of proximally migrated pancreatic duct stents. Gastrointest Endosc 2009;70:174-179.
4. Vila JJ, Marcos K, Manuel PM. Retrieval of proximally migrated pancreatic stents. Video Journal and Encyclopedia of GI Endoscopy 2013;1:584-587.

5. Lahoti S, Catalano MF, Geenen JE, Schmalz MJ. Endoscopic retrieval of proximally migrated biliary and pancreatic stents: experience of a large referral center. Gastrointest Endosc 1998;47:486-491.

6. Sherman S, Hawes RH, Uzer MF, Smith MT, Lehman GA. Endoscopic stent exchange using a guide wire and mini-snare. Gastrointest Endosc 1993;39:794-799.

7. Kim MJ, Han JH, Kang MH, Chae HB, Park SM, Youn SJ. Removal of a deeply migrated pancreatic stent in a normal-size pancreatic duct using a modified snare with a cut plastic sheath. Endoscopy 2012;44 Suppl 2 UCTN:E308-E309.

8. Rerknimitr R, Phuangsombat W, Naprasert P. Endoscopic removal of proximally migrated pancreatic stent by a grasping tripod. Endoscopy 2007;39 Suppl 1:E42. 